\title{
Cardiorespiratory Responses to Hypoxia and Hypercapnia at Rest in Vocalists
}

\author{
Miharu MIYAMURA, Koji ISHIDA, Keisho KataYAmA, Yasutake SATO, Yoshifumi Morotome, \\ Norihiro SHIMA, Hiroshi MATSUO, and Kohei SATO
}

Research Center of Health, Physical Fitness and Sports, Nagoya University, Nagoya, 464-8601 Japan

\begin{abstract}
In order to clarify whether or not ventilatory and circulatory responses to hypoxia and hypercapnia at rest in male vocalists $(n=11)$ are identical to those of untrained subjects $(n=11)$, ventilatory responses to hypoxia (HVR) and hypercapnia (HCVR) were estimated as the slope of regression relating $\dot{V}_{1}$ to $\mathrm{Sa}_{\mathrm{O}_{2}}$ $\left(\Delta \dot{V} \mathrm{l} / \Delta \mathrm{Sa}_{\mathrm{O}_{2}}\right)$ or the slope factor $(A)$ for the $\dot{V} 1-P \mathrm{ET}_{\mathrm{O}_{2}}$ curve, and as the slope of regression relating $\dot{V} \mathrm{I}$ to $P \mathrm{ET}_{\mathrm{CO}_{2}}\left(\Delta \dot{V} \mathrm{l} / \Delta P \mathrm{ET}_{\mathrm{CO}_{2}}\right)$, respectively. The respiratory frequency $(f)$, tidal volume $(V T)$, heart rate $(\mathrm{HR})$, and blood pressure $(\mathrm{BP})$ responses to hypoxia and hypercapnia were also estimated as the slope of the line calculated by linear regression related to $\mathrm{Sa}_{\mathrm{O}_{2}}$ and $\mathrm{PET}_{\mathrm{CO}_{2}}$. Mean values of $\Delta \dot{V} \mathrm{l} / \Delta S_{\mathrm{O}_{2}}$ and $A$ as an index of hypoxic ventilatory response were lower in the vocalist group $\left(0.39 \pm 0.25 / \cdot \mathrm{min}^{-1} \cdot \%^{-1}\right.$ and $76.8 \pm 55.7 / \cdot \mathrm{min}^{-1} \cdot$ torr $\left.^{-1}\right)$ than that in the control

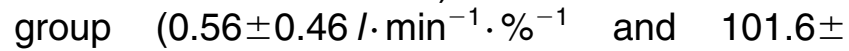
$85.4 / \cdot \mathrm{min}^{-1} \cdot$ torr $\left.^{-1}\right)$, and there was no statisti-

cally significant difference. The $\Delta f / \Delta \mathrm{Sa}_{\mathrm{O}_{2}}$ was significantly $(p<0.05)$ lower in the vocalist group $\left(-0.02 \pm 0.39\right.$ breaths $\left.\cdot \min ^{-1} \cdot \%^{-1}\right)$ than that in the control group $\left(0.43 \pm 0.65\right.$ breaths $\cdot \mathrm{min}^{-1}$. $\left.\%^{-1}\right)$. In contrast, mean values of $\Delta \dot{V} \mathrm{I} / \Delta P \mathrm{ET}_{\mathrm{CO}_{2}}$ per body mass index were significantly $(p<0.05)$ lower in the vocalist group $(0.05 \pm 0.03$ $1 \cdot \min ^{-1} \cdot$ torr $\left.^{-1}\right)$ than those in the control group $\left(0.10 \pm 0.06 / \cdot \mathrm{min}^{-1} \cdot\right.$ torr $\left.^{-1}\right)$. There were also significant differences in $\Delta V \mathrm{~T} / \Delta P \mathrm{ET}_{\mathrm{CO}_{2}}$ and $\Delta f / \Delta P \mathrm{ET}_{\mathrm{CO}_{2}}$ between the two groups $(p<0.05)$. However, no significant differences in HR and BP responses to hypoxia and hypercapnia between the two groups were observed. These results suggest that the magnitude of ventilatory response, but not HR and BP, to hypoxia and hypercapnia at rest in vocalists is reduced by chronic vocal training, including breath control and elongation of phonation for long periods. [Japanese Journal of Physiology, 53, 17-24, 2003]
\end{abstract}

Key words: vocalist, ventilatory response, circulatory response, hypoxia, hypercapnia.

It It has hitherto been reported that hypoxic and hypercapnic ventilatory responses at rest are lower in the well-trained athletes, long-distance swimmers, and elite synchronized swimmers as compared to untrained subjects [1-3]. Furthermore, there are several studies concerning blunted ventilatory responses to hypoxia and hypercapnia in free divers (e.g., Igarashi [4] showed reduced hypercapnic ventilatory responses in the ama, people who harvest shellfish and seaweed only during harvest seasons using no special breathing apparatus). It has been confirmed by a few authors [5-7] that divers, compared to nondivers, had a blunted chemosensitivity to hypercapnia. Masuda et $a l$. $[8,9]$ also indicated decreased ventilatory response to hypercapnia in the Funado, people who dive to depths of 10-20 m, and to hypoxia in the Kachido, people who dive at shallow depths of 5-10 m, respectively.

On the other hand, a unique group of musicians, formal classical singers, or so-called professional vocalists, perform vigorous respiratory exercise while extending their breath and may need to be endowed with special characteristics in their control of ventilation, which allow them to perform at an elite level of

Received on August 28, 2002; accepted on December 6, 2002

Correspondence should be addressed to: Miharu Miyamura, Research Center of Health, Physical Fitness and Sports, Nagoya University, Nagoya, 464-8601 Japan. Tel: +81-52-789-3956, Fax: +81-52-789-3957, E-mail: miyamura@htc.nagoya-u.ac.jp 
competition. Although unique phonation in professional vocalists seems to be gradually possible itself with voice training for long periods, we have recently determined ventilatory response to hypercapnia at rest in a well-trained professional male yogi, who is able to breath at a frequency of once per minute (Ujjai respiration) for an hour. The slope of hypercapnic ventilatory response curve measured by the rebreathing method in this subject was $0.26 \mathrm{l} \cdot \mathrm{min}^{-1} \cdot$ torr $^{-1}$. This corresponds to about $25 \%$ of healthy untrained subjects [10]. These results suggest that lower chemosensitivity of hypoxia and hypercapnia observed in welltrained athletes, long-distance swimmers, divers, and yogi seems to be related to adaptations of hypoxic and hypercapnic exposure by the respiratory mode which includes holding ones breath. If so, it is possible to hypothesize that hypoxic and hypercapnic ventilatory responses are lower in vocalists than that in untrained subjects. These characteristics may result in lower work and less dyspnea during singing, which may offer a competitive advantage. To our knowledge, however, there are no available data with regard to the respiratory chemosensitivity of vocalists.

The purpose of this study, therefore, was to clarify whether or not ventilatory and circulatory responses to hypoxia and hypercapnia in vocalists is the same as compared to untrained subjects.

\section{METHODS}

Subjects. Healthy young male volunteers were recruited from two universities. Eleven untrained subjects (control group) were students of one university and the other 11 subjects (vocalist group) were students who belong to the Department of Vocal Music of an art university. The students of the vocalist group had trained mainly by vocalization or phonation for 2-3 h daily, 5-6 times a week year-round for 1-6 (average 3.4) years. Mean values and standard deviations $( \pm \mathrm{SD})$ for age, height, body mass, and body mass index (BMI) were $21.4(1.6)$ years, $170.8(4.1) \mathrm{cm}$, 70.3 (14.6) kg, and 23.9 (3.9) for the vocalist group, and 19.9 (1.4) years, $174.4(4.7) \mathrm{cm}, 63.4(6.1) \mathrm{kg}$, and 21.0 (2.1) for the control group. With the exception of age, no significant difference was found in height, body mass, or BMI between the two groups. All subjects were explained the potential risks and discomforts of the experiments and signed an informed consent form approved by the Human Research Committee of the Research Center of Health, Physical Fitness and Sports of Nagoya University.

Preliminary test. All subjects came to the laboratory at least three times on separate days. They were instructed as to the experimental procedures, but not informed as to the purpose and results of this study until its completion. On the first day, all subjects were familiarized only with the apparatus and testing procedures involved in this study; subjects performed a preliminary test to become sufficiently accustomed to cycling on the bicycle ergometer and to rebreathing for measuring ventilatory responses to hypoxia and hypercapnia. Since most of the subjects had no experience of maximal exercise or rebreathing wearing a respiratory face mask or mouthpiece, the subjects were asked to wear these for determining respiratory gas volume even during the preliminary test. The actual experiment was conducted approximately 1 week after the first familiarization. The subjects were asked to avoid intense exercise and participated $2 \mathrm{~h}$ after their last meal.

Maximal bicycle exercise. On the second day, which was several days after the first day, a maximal bicycle exercise test was conducted in order to estimate the aerobic work capacity of each subject. The maximal exhaustive exercise was carried out using stepwise incremental loading. The cycling exercise test began at an initial power output of $60 \mathrm{~W}$, and the work load was increased $30 \mathrm{~W}$ every 2 min until exhaustion. The pedaling frequency was kept constant at $60 \mathrm{rpm}$ with the aid of a metronome. A respiratory mask and electrodes were attached to each subject's face and chest to continuously determine pulmonary ventilation $(\dot{V} \mathrm{E})$, oxygen uptake $\left(\dot{V} \mathrm{O}_{2}\right)$, carbon dioxide output $\left(\dot{V}_{\mathrm{CO}_{2}}\right)$, and heart rate (HR) during maximal exhaustive exercise (i.e., during maximal bicycle exercise, expired gases were collected into a Douglas bag every minute until exhaustion). Expired gas volume was measured with a wet-gasmeter (type WE, Shinagawa, Tokyo, Japan). Gas analysis was performed by means of an $\mathrm{O}_{2}$ and $\mathrm{CO}_{2}$ analyzer (type MG-360, Minato Ikagaku, Osaka, Japan). An electrocardiogram was continuously recorded to estimate HR throughout the maximal exercise. The peak HR and pulmonary ventilation were expressed as $\mathrm{HR}_{\max }$ and $\dot{V}_{\mathrm{max}}$, respectively. Oxygen uptake derived during maximal exercise was considered to be maximum oxygen uptake $\left(\dot{V}_{2}{ }_{2 \max }\right)$ when two of the following three criteria were satisfied: identification of a plateau in $\dot{V}_{2}$ with an increase in power output $\left(<150 \mathrm{ml} \dot{V}_{\mathrm{O}_{2}}\right.$ increase), $\mathrm{HR} \pm 10 \%$ of age-predicted maximum $(220-$ age $)$, and respiratory exchange ratio $\geqq 1.0[11,12]$.

Ventilatory and circulatory responses to hypoxia. Ventilatory response to hypoxia (HVR) at rest was determined using a progressive isocapnic hypoxic test proposed by Weil et al. [13]; the subject rebreathed a mixture gas in small bag connected to a 
closed circuit that had been used by Ohyabu et al. [14] after the subject rested in sitting position for $30 \mathrm{~min}$. In the HVR test, tidal volume $(V T)$, respiratory frequency $(f)$, minute inspiratory volume $(\dot{V} \mathrm{I})$, inspiratory duration $(T \mathrm{I})$, end-tidal oxygen and carbon dioxide concentrations $\left(\mathrm{FET}_{\mathrm{O}_{2}}\right.$ and $\left.F \mathrm{ET}_{\mathrm{CO}_{2}}\right)$, arterial blood pressure (BP), and arterial oxygen saturation $\left(\mathrm{Sa}_{\mathrm{O}_{2}}\right)$ were continuously determined during rebreathing. The subject breathed through a mouthpiece attached to a hot-wire flowmeter (type RF-H, Minato Ikagaku). Sample gas was drawn through a sampling tube connected to a mouthpiece and $F \mathrm{ET}_{\mathrm{O}_{2}}$ and $F \mathrm{ET}_{\mathrm{CO}_{2}}$ were analyzed using a gas analyzer (type MG-360, Minato Ikagaku). End-tidal partial pressure of oxygen and carbon dioxide $\left(P \mathrm{ET}_{\mathrm{O}_{2}}\right.$ and $\left.P \mathrm{ET}_{\mathrm{CO}_{2}}\right)$ were calculated from $F \mathrm{ET}_{\mathrm{O}_{2}}$ and $F \mathrm{ET}_{\mathrm{CO}_{2}}$, respectively. Systolic blood pressure (SBP) and diastolic blood pressure (DBP) were recorded beat-by-beat with a Finapres device (Model 2300, Ohmeda, Nagoya, Japan) because the BP monitoring method by Finapres has been found to reliably reflect intra-arterial $\mathrm{BP}$ during a variety of physiological interventions $[15,16] . \mathrm{Sa}_{\mathrm{O}_{2}}$ was determined during rebreathing by a pulse oximeter positioned on the tip of the left forefinger (OVL-1200, Nihon Kohden, Tokyo, Japan). The finger cuff of the Finapres and the probe of the pulse oximeter were kept constantly at heart level. HR was also measured from an electrocardiogram (ECG) using three electrodes placed on the chest. The signals from the flowmeter, gas analyzer, Finapres, pulse oximeter, and electrocardiography were digitized at a sampling frequency of $100 \mathrm{~Hz}$ through analog-to-digital conversion (ADX-98H, Canopus, Kobe, Japan). The digitized signals were stored in a computer (PC-9821XA, NEC, Tokyo, Japan). The ventilatory parameters such as $\dot{V} \mathrm{I}, f, V \mathrm{~T}$, and mean inspiratory flow $(V \mathrm{~T} / \dot{V} \mathrm{I})$ were calculated breath-by-breath, and the circulatory parameters such as SBP, DBP, $S \mathrm{a}_{\mathrm{O}_{2}}$, and HR were monitored in beat-by-beat fashion [17], respectively. HVR was estimated as the slope of the line calculated by linear regression relating $\dot{V} \mathrm{I}$ to $S \mathrm{a}_{\mathrm{O}_{2}}\left(\Delta \dot{V} \mathrm{I} / \Delta S \mathrm{a}_{\mathrm{O}_{2}}\right.$, where $\Delta$ is change; in $l \cdot \min ^{-1} \cdot$ torr $\left.^{-1}\right)$, and the slope was presented as positive numbers by conversion. HVR was also assessed by the slope factor $(A$, $l \cdot \mathrm{min}^{-1} \cdot$ torr $\left.^{-1}\right)$ for the $\dot{V} \mathrm{I}-P \mathrm{ET}_{\mathrm{O}_{2}}$ curve [18]: $\dot{V} \mathrm{I}=\dot{V}_{0}+A /\left(P \mathrm{ET}_{\mathrm{O}_{2}}-32\right)$, where $\dot{V} \mathrm{I}$ is in $l \cdot \mathrm{min}^{-1} ; \dot{V}_{0}$ is the asymptote for ventilation obtained extrapolation; and 32 is the asymptote for $P \mathrm{ET}_{\mathrm{O}_{2}}$ in torr when $\dot{V} \mathrm{I}$ is infinite. Higher values of $\Delta \vec{V} \mathrm{I} / \Delta \mathrm{Sa}_{\mathrm{O}_{2}}$ and $A$ indicate higher ventilatory response to hypoxia and vice versa. Furthermore, the $V \mathrm{~T}, f$, SBP, DBP, and HR responses to isocapnic progressive hypoxia were estimated as the slope of the line calculated by linear regression re- lating to $\mathrm{Sa}_{\mathrm{O}_{2}}\left(\Delta V \mathrm{~T} / \Delta S \mathrm{Sa}_{\mathrm{O}_{2}}, l \cdot \%^{-1} ; \Delta f / \Delta \mathrm{Sa}_{\mathrm{O}_{2}}\right.$, breath . $\min ^{-1} \cdot \%{ }^{-1} ; \Delta \mathrm{SBP} / \Delta \mathrm{Sa}_{\mathrm{O}_{2}}, \mathrm{mmHg} \cdot \%^{-1} ; \Delta \mathrm{DBP} / \Delta \mathrm{Sa}_{\mathrm{O}_{2}}$, $\mathrm{mmHg} \cdot \%^{-1}, \Delta \mathrm{HR} / \Delta \mathrm{Sa}_{\mathrm{O}_{2}}$, beats $\cdot \mathrm{min}^{-1} \cdot \%^{-1}$, respectively), and the slopes were presented as positive numbers by conversion. Moreover, the breathing pattern to hypoxia was analyzed in terms of the slope and intercept $(M$ and $K)$ of the linear regression of ventilation to $V \mathrm{~T}$ as proposed by Hey et al. [19]: $\dot{V} \mathrm{I}=M(V \mathrm{~T}-K)$.

Ventilatory and circulatory responses to hypercapnia. Ventilatory response to hypercapnia (HCVR) at rest was determined by the rebreathing method after the subject rested in a sitting position for $30 \mathrm{~min}$; the subject rebreathed a gas mixture (about $7 \% \mathrm{CO}_{2}$ in $\mathrm{O}_{2}$ ) of 5-6l for $4 \mathrm{~min}$ as described by Read [20]. The recording of minute inspiratory volume $(\dot{V} \mathrm{I})$ and end-tidal carbon dioxide partial pressure $\left(P \mathrm{ET}_{\mathrm{CO}_{2}}\right)$ were basically made in a manner similar to the computing system used in the HVR test (i.e., the subject breathed through a mouthpiece connected to a hotwire flowmeter from a rebreathing bag in a plastic box). During rebreathing, tidal volume $(V \mathrm{~T})$, respiratory frequency $(f)$, minute inspiratory volume $(\dot{V} \mathrm{I})$, inspiratory duration $(T \mathrm{I})$, end-tidal oxygen and carbon dioxide concentration $\left(F \mathrm{ET}_{\mathrm{O}_{2}}\right.$ and $\left.F \mathrm{ET}_{\mathrm{CO}_{2}}\right)$, arterial BP, and arterial oxygen saturation $\left(\mathrm{Sa}_{\mathrm{O}_{2}}\right)$ were continuously measured using the same technique mentioned above. The $\dot{V} \mathrm{I}, V \mathrm{~T}, f$, SBP, DBP, and HR responses to hypercapnia were estimated as the slope of the line calculated by linear regression relating to $\triangle P \mathrm{ET}_{\mathrm{CO}_{2}}$ $\left(\Delta \dot{V} \mathrm{I} / \Delta P \mathrm{ET}_{\mathrm{CO}_{2}}, \quad l \cdot \mathrm{min}^{-1} \cdot \operatorname{torr}^{-1} ; \quad \Delta V \mathrm{~T} / \Delta P \mathrm{ET}_{\mathrm{CO}_{2}}\right.$, $l \cdot$ torr $^{-1} ; \quad \Delta f / \Delta P \mathrm{ET}_{\mathrm{CO}_{2}}, \quad$ breath $\cdot \mathrm{min}^{-1} \cdot \mathrm{torr}^{-1} ; \quad \Delta \mathrm{SBP} /$ $\Delta P \mathrm{ET}_{\mathrm{CO}_{2}}, \mathrm{mmHg} \cdot$ torr $^{-1} ; \quad \Delta \mathrm{DBP} / \Delta P \mathrm{ET}_{\mathrm{CO}_{2}}, \mathrm{mmHg} \cdot$ torr $^{-1} ; \quad \Delta \mathrm{HR} / \Delta P \mathrm{ET}_{\mathrm{CO}_{2}}$, beats $\cdot \mathrm{min}^{-1} \cdot$ torr $^{-1}$, respectively). Higher values of $\Delta \dot{V} \mathrm{I} / \Delta P \mathrm{ET}_{\mathrm{CO}_{2}}, \Delta V \mathrm{~T} / \Delta P \mathrm{ET}_{\mathrm{CO}_{2}}$, and $\Delta f / \Delta P \mathrm{ET}_{\mathrm{CO}_{2}}$ indicate higher ventilatory response to hypercapnia and vice versa. In addition, the breathing pattern to hypercapnia was also analyzed in terms of the slope and intercept $\left(M^{\prime}\right.$ and $\left.K^{\prime}\right)$ of the linear regression of ventilation to tidal volume using the equation of Hey et al. $\left(\dot{V} \mathrm{I}=\mathrm{M}^{\prime}\left(V \mathrm{~T}-\mathrm{K}^{\prime}\right)\right)[19]$.

To clarify the relation between body size and ventilatory response to hypoxia and hypercapnia, BMI (sometimes called the Quetelet Index), weight in $\mathrm{kg}$ divided by square of height in $\mathrm{m}\left(W / H^{2}\right)$, was calculated for each subject [21].

Statistical analysis. Values are expressed as mean and standard deviation $( \pm \mathrm{SD})$. The comparisons of all parameters between the vocalists and controls were made using a non-parametric test (MannWhitney's $U$-test). The relationship among the parameters was determined by simple linear regression analysis. The SPSS statistical package was used for these analyses. The level of significance was set at $5 \%$. 


\section{RESULTS}

Table 1 shows cardiorespiratory response to maximal bicycle ergometer exercise in the control and vocalist groups. Mean values and $\pm \mathrm{SD}$ of maximum oxygen uptake $\left(\dot{V}_{2}{ }_{2 \max }\right)$ and maximum pulmonary ventilation $\left(\dot{V} \mathrm{E}_{\max }\right)$ were $2.89 \pm 0.51$ and $122.5 \pm 24.4 l \cdot \mathrm{min}^{-1}$ for

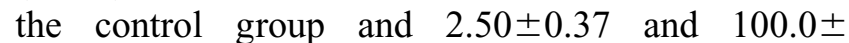
$15.7 l \cdot \mathrm{min}^{-1}$ for the vocalist group, respectively. $\dot{V} \mathrm{O}_{2 \max }$ and $\dot{V} \mathrm{E}_{\max }$ were significantly lower in the vocalist group than that in the control group $(p<0.05)$, while there were no significant differences in maximal heart rate $\left(\mathrm{HR}_{\max }\right)$, respiratory exchange ratio (RER) or ratios of maximal pulmonary ventilation to maximum oxygen uptake or maximum carbon dioxide output $\left(\dot{V} \mathrm{E}_{\max } / \dot{V} \mathrm{O}_{2 \max }\right.$ or $\left.\dot{V} \mathrm{E}_{\max } / \dot{V} \mathrm{CO}_{2 \max }\right)$.

Mean values of $\Delta \dot{V} \mathrm{I} / \Delta S \mathrm{a}_{\mathrm{O}_{2}}$ and $A$ as an index ventilatory response to hypoxia were $0.56 \pm 0.46 l \cdot \mathrm{min}^{-1}$. $\%^{-1}$ and $101.6 \pm 85.4 l \cdot \mathrm{min}^{-1} \cdot$ torr $^{-1}$ in the control group and $0.39 \pm 0.25 l \cdot \mathrm{min}^{-1} \cdot \%^{-1}$ and $76.8 \pm 55.7$ $l \cdot \mathrm{min}^{-1} \cdot \mathrm{torr}^{-1}$ in the vocalist group, respectively. Although there were no significant differences in the $\Delta \dot{V} \mathrm{I} / \Delta S \mathrm{a}_{\mathrm{O}_{2}}$ and $A$ between the control and vocalist groups, $\Delta f / \Delta S \mathrm{a}_{\mathrm{O}_{2}}$ and $M$ were significantly lower in the vocalist group $\left(-0.02 \pm 0.39 \mathrm{breath} \cdot \mathrm{min}^{-1} \cdot \%^{-1}\right.$ and $5.9 \pm 4.1 \mathrm{~min}^{-1}$ ) than that in the control group $\left(0.43 \pm 0.65\right.$ breath $\cdot \min ^{-1} \cdot \%^{-1}$ and $\left.11.9 \pm 6.8 \mathrm{~min}^{-1}\right)$ as shown in Table $2(p<0.05)$.

Table 3 indicates the results of hypercapnic ventilatory response at rest in both groups. Mean values of $\Delta \dot{V} / \Delta P \mathrm{ET}_{\mathrm{CO}_{2}}$ per body mass index (HCVR/BMI) as an index of ventilatory response to hypercapnia was significantly lower in the vocalist group $(0.05 \pm$ $0.03 \mathrm{l} \cdot \mathrm{min}^{-1} \cdot$ torr $\left.^{-1}\right)$ than that in the control group $\left(0.10 \pm 0.06 \mathrm{l} \cdot \mathrm{min}^{-1} \cdot\right.$ torr $\left.^{-1}\right)(p<0.05)$, while no significant difference was found in the HCVR

Table 1. Cardiorespiratory responses to maximal bicycle exercise in the control and vocalist groups.

\begin{tabular}{lcc}
\hline & Control & Vocalist \\
\hline $\mathrm{HR}_{\max }($ beats $/ \mathrm{min})$ & $199.8 \pm 9.4$ & $200.2 \pm 9.5$ \\
$\dot{V} \mathrm{E}_{\max }(/ / \mathrm{min})$ & $120.9 \pm 23.9$ & $100.0 \pm 15.7^{*}$ \\
$\dot{V} \mathrm{O}_{2 \max }(/ / \mathrm{min})$ & $2.88 \pm 0.49$ & $2.50 \pm 0.37^{*}$ \\
$\dot{V} \mathrm{O}_{2 \max } / \mathrm{BW}(\mathrm{ml} / \mathrm{kg} / \mathrm{min})$ & $45.4 \pm 5.5$ & $36.2 \pm 4.9^{*}$ \\
$\dot{V} \mathrm{CO}_{2 \max } / \mathrm{BW}(\mathrm{ml} / \mathrm{kg} / \mathrm{min})$ & $53.1 \pm 6.3$ & $43.7 \pm 6.8^{*}$ \\
$\mathrm{RER}$ & $1.17 \pm 0.08$ & $1.21 \pm 0.08$ \\
\hline
\end{tabular}

Values are means $\pm S D$. $H R_{\max }$, maximum heart rate; $\dot{V}_{\max }$, maximum pulmonary ventilation; $\dot{V}_{2 \text { max }}$, maximum oxygen uptake; $\dot{V} \mathrm{O}_{2 \max } / \mathrm{BW}$, maximum oxygen uptake per kilogram of body weight; $\dot{V} \mathrm{CO}_{2 \text { max }} / \mathrm{BW}$, maximum carbon dioxide output per kilogram of body weight; RER, respiratory exchange ratio. ${ }^{\star}$ Significantly different from control, $p<0.05$.
$\left(\Delta \dot{V} \mathrm{I} / \Delta P \mathrm{ET}_{\mathrm{CO}_{2}}\right)$ values of the control and vocalist groups. Furthermore, it was found that $\Delta V \mathrm{~T} / \Delta P \mathrm{ET}_{\mathrm{CO}_{2}}$ was significantly higher in the vocalist group $\left(79.4 \pm 41.6 l \cdot\right.$ torr $\left.^{-1}\right)$ than in the control group $\left(40.8 \pm 39.2 l \cdot\right.$ torr $\left.^{-1}\right)(p<0.05)$, and that $\Delta f / \Delta P \mathrm{ET}_{\mathrm{CO}_{2}}$ and $K^{\prime}$ were significantly lower in the vocalist group $\left(0.08 \pm 0.88\right.$ breath $\cdot \mathrm{min}^{-1} \cdot$ torr $^{-1}$ and $\left.0.19 \pm 1.07 l\right)$ than in the control group $(0.86 \pm 0.92$ breath . $\mathrm{min}^{-1} \cdot$ torr $^{-1}$ and $\left.0.91 \pm 0.46 l\right) \quad(p<0.05)$, respectively.

Table 2. Ventilatory response to hypoxia at rest in the control and vocalist groups.

\begin{tabular}{lcc}
\hline & Control & Vocalist \\
\hline $\mathrm{HVR}(/ / \mathrm{min} / \%)$ & $0.56 \pm 0.46$ & $0.39 \pm 0.25$ \\
$\mathrm{HVR} / \mathrm{BMI}(/ / \mathrm{min} / \%)$ & $0.026 \pm 0.022$ & $0.016 \pm 0.010$ \\
$A(/ / \mathrm{min} / \mathrm{torr})$ & $101.6 \pm 85.4$ & $76.8 \pm 55.7$ \\
$\mathrm{~A} / \mathrm{BMI}(/ / \mathrm{min} / \mathrm{torr})$ & $4.79 \pm 3.98$ & $3.17 \pm 2.15$ \\
$\dot{V}_{0}(/ / \mathrm{min})$ & $7.72 \pm 2.14$ & $6.55 \pm 2.25$ \\
$\Delta V \mathrm{~T} / \Delta \mathrm{Sa}_{\mathrm{O}_{2}}(/ / \%)$ & $21.9 \pm 15.5$ & $41.8 \pm 46.4$ \\
$\Delta f / \Delta \mathrm{Sa}_{\mathrm{O}_{2}}($ breath/min/\%) & $0.43 \pm 0.65$ & $-0.02 \pm 0.39^{*}$ \\
$M\left(\mathrm{~min}^{-1}\right)$ & $11.9 \pm 6.8$ & $5.9 \pm 4.1^{*}$ \\
$K(/)$ & $0.42 \pm 0.33$ & $0.61 \pm 0.56$ \\
\hline
\end{tabular}

Values are means $\pm S D$. HVR, hypoxic ventilatory response $\left(\Delta \dot{V} \mathrm{E} / \Delta \mathrm{Sa}_{\mathrm{O}_{2}}\right) ; \mathrm{HVR} / \mathrm{BMI}$, hypoxic ventilatory response per body mass index; $\Delta V \mathrm{~T} / \Delta \mathrm{Sa}_{\mathrm{O}_{2}}$, tidal volume response to hypoxia; $\Delta f / \Delta \mathrm{Sa}_{\mathrm{O}_{2}}$, respiratory frequency response to hypoxia; $A$, the slope constant of hypoxic ventilatory response curve; $A / B M I$, the slope constant of hypoxic ventilatory response curve per body mass index; $\dot{V}_{0}$, the horizontal asymptote in ventilation for infinite; $M$, slope of linear relation between pulmonary ventilation ( $\left.\dot{V}^{\mathrm{E}}\right)$ and tidal volume $\left(V_{T} \mathrm{~T}\right)$; $K$, intercept on the $V T$ axis. * Significantly different from control, $p<0.05$.

Table 3. Ventilatory response to hypercapnia at rest in the control and vocalist groups.

\begin{tabular}{lll}
\hline & \multicolumn{1}{c}{ Control } & \multicolumn{1}{c}{ Vocalist } \\
\hline $\mathrm{HCVR}(/ / \mathrm{min} /$ torr $)$ & $2.00 \pm 1.17$ & $1.25 \pm 0.76$ \\
$\mathrm{HCVR} / \mathrm{BMI}(/ /$ min/torr $)$ & $0.10 \pm 0.06$ & $0.05 \pm 0.03^{\star}$ \\
$B($ torr $)$ & $48.6 \pm 3.3$ & $45.8 \pm 4.4$ \\
$\Delta V \mathrm{~T} / \Delta \mathrm{ETT}_{\mathrm{CO}_{2}}$ (//torr) & $40.8 \pm 39.2$ & $79.4 \pm 41.6^{\star}$ \\
$\Delta f / \Delta P \mathrm{ET}_{\mathrm{CO}_{2}}$ (breath/torr) & $0.86 \pm 0.92$ & $0.08 \pm 0.88^{\star}$ \\
$M^{\prime}\left(\mathrm{min}^{-1}\right)$ & $15.8 \pm 12.3$ & $12.5 \pm 7.8$ \\
$K^{\prime}(I)$ & $0.91 \pm 0.46$ & $0.19 \pm 1.07^{\star}$
\end{tabular}

Values are means $\pm S D$. HCVR, hypercapnic ventilatory response $\left(\Delta \dot{V} \mathrm{E} / \Delta \mathrm{PET}_{\mathrm{CO}_{2}}\right)$; $\mathrm{HCVR} / \mathrm{BMI}$, hypercapnic ventilatory response per body mass index; $B$, extrapolated intercept on the abscissa ( $P \mathrm{~A}_{\mathrm{CO}_{2}}$ axis); $\Delta V \mathrm{~T} / \Delta P \mathrm{ET}_{\mathrm{CO}_{2}}$, tidal volume response to hypercapnia; $\Delta f / \Delta P \mathrm{ET}_{\mathrm{CO}_{2}}$, respiratory frequency response to hypercapnia; $M^{\prime}$, slope of linear relation between pulmonary ventilation ( $\dot{V} \mathrm{E})$ and tidal volume $(V T) ; K^{\prime}$, intercept on the $V T$ axis. ${ }^{*}$ Significantly different from control, $p<0.05$. 
Table 4. Heart rate and blood pressure responses to hypoxia and hypercapnia at rest in the control and vocalist groups.

\begin{tabular}{lrr}
\hline & Control & \multicolumn{1}{c}{ Vocalist } \\
\hline$\Delta \mathrm{HR} / \Delta \mathrm{Sa}_{\mathrm{O}_{2}}$ (beat/min/\%) & $1.08 \pm 0.48$ & $0.97 \pm 0.40$ \\
$\Delta \mathrm{SBP} / \Delta \mathrm{Sa}_{\mathrm{O}_{2}}(\mathrm{mmHg} / \%)$ & $0.56 \pm 1.07$ & $0.54 \pm 0.66$ \\
$\Delta \mathrm{DBP} / \Delta \mathrm{Sa}_{\mathrm{O}_{2}}(\mathrm{mmHg} / \%)$ & $0.04 \pm 0.35$ & $0.17 \pm 0.46$ \\
$\Delta \mathrm{HR} / \Delta P \mathrm{ET}_{\mathrm{CO}_{2}}$ (beat/min/torr) & $0.35 \pm 0.82$ & $-0.03 \pm 0.41$ \\
$\Delta \mathrm{SBP} / \Delta P \mathrm{ET}_{\mathrm{CO}_{2}}$ (mmHg/torr) & $1.43 \pm 1.53$ & $1.13 \pm 0.75$ \\
$\Delta \mathrm{DBP} / \Delta P \mathrm{ET}_{\mathrm{CO}_{2}}$ (mmHg/torr) & $0.74 \pm 0.50$ & $0.57 \pm 0.52$ \\
\hline
\end{tabular}

Values are means $\pm \mathrm{SD} . \Delta \mathrm{HR} / \Delta \mathrm{Sa}_{\mathrm{O}_{2}}$, heart rate response to hypoxia; $\Delta \mathrm{SBP} / \Delta \mathrm{Sa}_{\mathrm{O}_{2}}$, systolic blood pressure response to hypoxia; $\Delta \mathrm{DBP} / \Delta \mathrm{Sa}_{2}$, diastolic blood pressure response to hypoxia; $\Delta \mathrm{HR} / \Delta P \mathrm{ET}_{\mathrm{CO}_{2}}$, heart rate response to hypercapnia; $\Delta \mathrm{SBP} / \Delta P \mathrm{ET}_{\mathrm{CO}_{2}}$, systolic blood pressure response to hypercapnia; $\triangle \mathrm{DBP} / \Delta P \mathrm{ET}_{\mathrm{CO}_{2}}$, diastolic blood pressure response to hypercapnia.
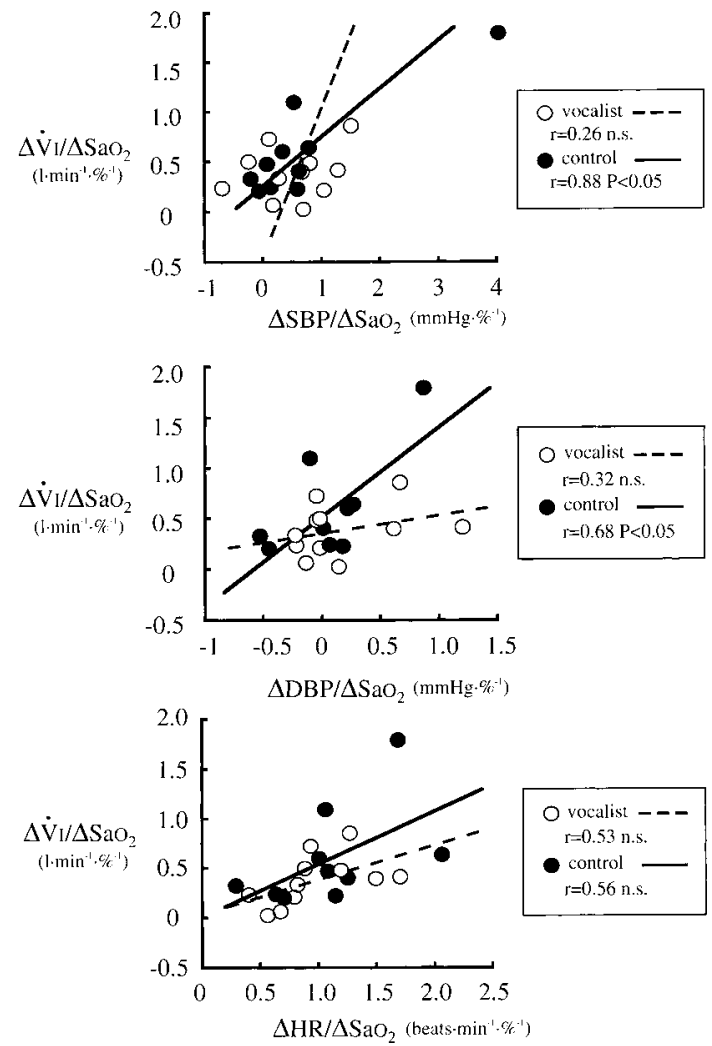

Fig. 1. Relationships between hypoxic ventilatory response $\left(\Delta \dot{V} \mathrm{l} / \Delta \mathrm{Sa}_{\mathrm{O}_{2}}\right)$ and hypoxic systolic, diastolic blood pressure, and heart rate responses $\left(\Delta \mathrm{SBP} / \Delta \mathrm{Sa}_{\mathrm{O}_{2}}\right.$, $\left.\Delta \mathrm{DBP} / \Delta \mathrm{Sa}_{\mathrm{O}_{2}}, \Delta \mathrm{HR} / \Delta \mathrm{Sa}_{\mathrm{O}_{2}}\right)$ in the vocalist $(\bigcirc)$ and control (O) groups.

There were no significant differences in HR and BP responses to hypoxia and hypercapnia between the control and vocalist groups as shown in Table 4.

Figure 1 shows the relationship between ventilatory response and circulatory response to hypoxia in both control and vocalist groups. There are significant cor-
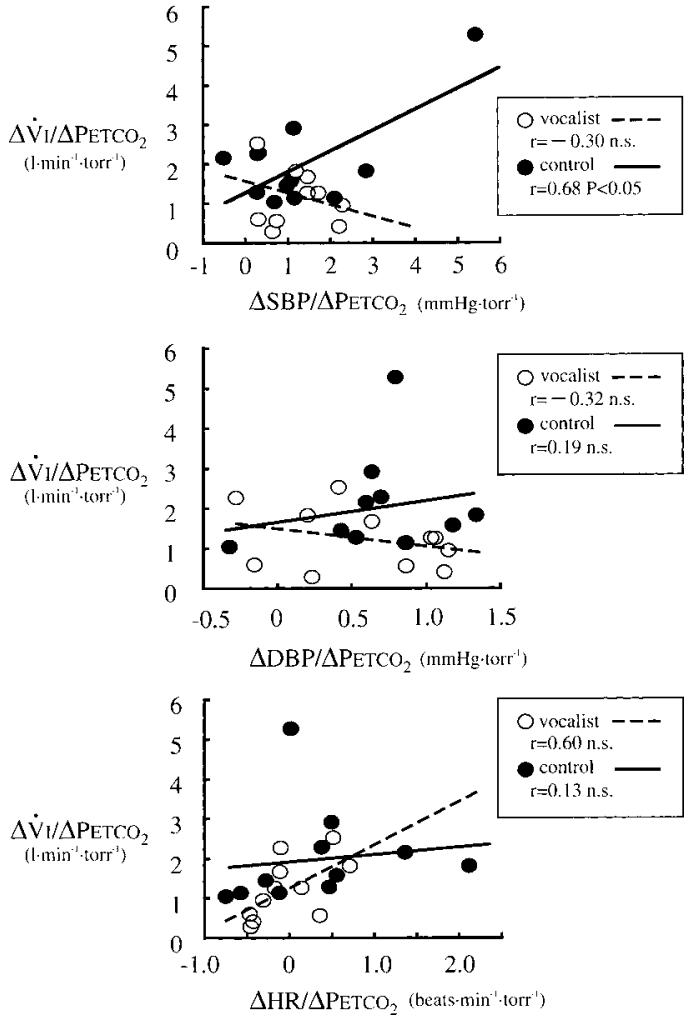

Fig. 2. Relationships between hypercapnic ventilatory response $\left(\Delta \dot{V} \mathrm{l} / \Delta \mathrm{PET}_{\mathrm{CO}_{2}}\right)$ and hypercapnic systolic, diastolic blood pressure, and heart rate responses

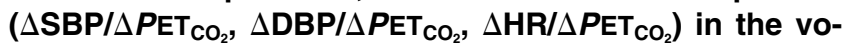
calist $(\bigcirc)$ and control $(\odot)$ groups.

relations between not only $\Delta \dot{V} \mathrm{I} / \Delta S \mathrm{a}_{\mathrm{O}_{2}}$ and $\Delta \mathrm{SBP} / \Delta S \mathrm{Sa}_{\mathrm{O}_{2}}(r=0.88, p<0.05)$, but also $\Delta \dot{V} \mathrm{I} / \Delta \mathrm{Sa}_{\mathrm{O}_{2}}$ and $\Delta \mathrm{DBP} / \Delta \mathrm{Sa}_{\mathrm{O}_{2}}(r=0.68, p<0.05)$ in the control group. As shown in Fig. 2, furthermore, a significant correlation between $\Delta \mathrm{SBP} / \Delta P \mathrm{ET}_{\mathrm{CO}_{2}}$ and $\Delta \dot{V} \mathrm{I} / \Delta P \mathrm{ET}_{\mathrm{CO}_{2}}$ $(r=0.68, p<0.05)$ was found in the control group. However, no significant correlation was found between BP and ventilatory responses to hypoxia and hypercapnia in the vocalist group. In addition, no significant correlation was found between ventilatory response and HR response to hypoxia and hypercapnia in both groups, as shown in Figs. 1 and 2.

\section{DISCUSSION}

The main observation arising from the present study was that the examined vocalists are indeed characterized by: (1) lower respiratory frequency responses to hypoxia and hypercapnia, (2) a blunted ventilatory response to hypercapnia, and (3) no significant correlation between ventilatory response and SBP response to hypoxia and hypercapnia. To our knowledge, this is perhaps the first study of respiratory and circulatory responses to hypoxia and hypercapnia in vocalists. 
Phonation requires close coordination between two mechanical processes: (1) movement of the vocal cords and supralaryngeal muscles, which together determines pitch and loudness, and (2) movement of the respiratory bellows, which provides the subglottic pressure and glottal airflow needed to drive the sound generator [22]. To generate a tone of constant loudness and pitch, it is necessary that, during phonation, subglottic pressure remains constant so that air in the lungs is pushed by means of a ventilatory apparatus while singing. Vital capacity, which is an index of lung volume or the ventilatory apparatus for each vocalist, seems to be one of the important factors of phonation time. In previous studies, lung volume determinations such as vital capacity, forced expiatory volume, functional residual volume, and maximum breathing capacity were made for professional vocalists by several authors [23-25] (e.g., Heller et al. [23] measured the lung volumes of 16 professional singers and 21 subjects who had no professional vocal training). They have reported that, in terms of the various divisions of lung volume, no significant difference was noted between the mean values obtained from the normal control group as compared with the mean values found for the vocalist group. These results have been confirmed by White [26]. Further, Bouhuys et al. [22], who found that the recording of volume events during the singing of "Prayer of Thanksgiving," showed no clear-cut differences between trained and untrained singers, and no clear relation to the subject's vital capacity. From these results, they suggest that other respiratory tests designed to test the control of respiration would reveal differences between individuals in the groups.

It has previously been reported that maximal oxygen uptake $\left(\dot{V}_{\mathrm{O}_{2} \max }\right)$, as an index of maximum aerobic work capacity of humans, is greater in endurance athletes than in untrained subjects, and hypoxic and hypercapnic ventilatory responses at rest are lower in well-trained athletes, marathon runners, and endurance swimmers [1, 2, 27]. Higher maximum oxygen uptake and reduced hypoxic and hypercapnic ventilatory responses observed in trained athlete groups are considered to be the result of adaptation to endurance training using muscles of the upper and lower limbs for long periods of time [28, 29]. To our knowledge, however, there are no available data concerning the maximum oxygen uptake and respiratory chemosensitivity of singers as known voice athletes or professional vocalists. Thus, we determined maximum oxygen uptake during maximal exhaustive exercise and ventilatory and circulatory responses to hypoxia and hypercapnia at rest in vocalists. In the present study, maximum oxygen uptake $\left(\dot{V}_{2 \text { max }}\right)$ was significantly lower in the vocalist group than that in the control group $(p<0.05)$ (Table 1). Nevertheless, a blunted ventilatory response to hypercapnia was observed in the vocalist group as compared to the control group. The disparity in the relationship between maximum oxygen uptake and hypercapnic chemosensitivity in endurance athletes and vocalists seems to be due to the difference in the muscles mobilized during training (i.e., muscles of upper and lower limbs in endurance athletes and respiratory muscles in the vocalists). In other words, decrements of hypercapnic chemosensitivity in the vocalist may be related to the respiratory mode and pattern in daily vocal training. That is, vocalists seem to be controlling the breathing themselves using so-called respiratory muscles, forcefully, weakly and/or quickly and slowly, to maintain varying pitches and loudness during phonation training or singing for long periods. It is possible to assume that intensive and prolonged practice of various phonations using respiratory muscles may have elements in common with the adaptation of respiratory chemosensitvity to endurance training using skeletal muscles, even if maximum oxygen uptake does not increase during vocal training.

Similarly, it is well known that the practice of hatha-yoga consists of control of posture (asana) and manipulation of respiration (pranayama), and practitioners of yoga, known as yogi, have more tidal volume and less respiratory frequency than untrained subjects. Miles [30] has reported that mean values of minute ventilation and respiratory frequency during ujjai respiration for $20 \mathrm{~min}$ were $3.53 \mathrm{l} \cdot \mathrm{min}^{-1}$ and 1.26 breaths $\cdot \mathrm{min}^{-1}$. Stanescu et al. [31] found that the ventilatory response to hypercapnia was significantly lower in Belgian subjects who had made an intensive practice of hatha-yoga as compared to an untrained group. Recently, we also observed that the slope $(S)$ of the hypercapnic ventilatory response curve (i.e., measured by the rebreathing method) of a well-trained Japanese hatha-yogi, who is able to breathe once a minute for an hour, was $0.26 l \cdot \mathrm{min}^{-1} \cdot$ torr $^{-1}$. This corresponds to $37 \%$ of Stanescu et al.'s value and about $25 \%$ of a healthy untrained subject, respectively. Since arterial $\mathrm{pH}$ decreased to 7.319 and arterial carbon dioxide partial pressure $\left(\mathrm{Pa}_{\mathrm{CO}_{2}}\right)$ increased to 51.3 torr at the end of ujjai respiration of once per minute in the hatha-yogi, it was suggested that reduced hypercapnic chemosensitivity in the well-trained yogi may be related to the adaptation of a low arterial $\mathrm{pH}$ and/or high $\mathrm{Pa}_{\mathrm{CO}_{2}}$ [10]. In other words, the lower hypercapnic ventilatory response observed in vocalists could be due to adaptations of hypoxemia, hypercapnia, and/or 
acidemia as the result of voice training for long periods.

It was found in this study that blunted chemosensitivity to hypercapnia and lower respiratory frequency responses to hypoxia and hypercapnia were observed in the vocalist group as compared to the control group as shown in Tables 3 and 4 . These results suggest that vocal training may influence not only hypercapnic chemosensitivity, but also respiratory pattern, while the reason of change in the mechanical feedback mechanisms by vocal training is unknown. As described previously, however, the students of the vocalist group had trained mainly by vocalization and phonation for 2-3 h daily, 5-6 times a week yearround for 1-6 (average 3.4) years. They have been trained under the guidance of their professor to expel breath and resound with expired air without wasteful tension of the vocal cords. The manipulation of respiration during singing appears to mainly consist of near-vital capacity maneuvers that use not only the diaphragm and costal muscles, but also accessory respiratory muscles such as ujjai respiration. In other words, it is possible to assume that an intensive and prolonged practice of various phonations using the socalled respiratory muscles may have elements in common with the adaptation of respiratory chemosensitvity and respiratory pattern to ujjai respiration of hatha-yoga training, even though arterial blood gases were not determined in this study. This assumption, however, needs further investigation.

In the present study, the characteristic features seen in hypoxic and hypercapnic ventilatory activity were not accompanied by a similar trend in circulatory responses (i.e., there were no significant differences in HR and BP responses to hypoxia and hypercapnia between the vocalist and control groups (Table 4)). However, it is of interest that, in the vocalist group, no significant correlation was found between ventilatory response and SBP response to hypoxia and hypercapnia, while it was significantly correlated in the control group as shown in Figs. 1 and 2. At present, we cannot explain the discrepancy in the relationship between ventilatory response and SBP response to hypoxia and hypercapnia between the vocalist and control groups. However, the results should be considered in the light of effects of vocalist training on respiratory muscles. It has been reported that inspiratory muscle training resulting in a $32 \%$ increase in maximal inspiratory pressure does not change forced vital capacity (FVC), peak expiratory flow, $\dot{V}_{\mathrm{O}_{2} \text { max }}$, or work capacity [32], and that inspiratory muscle strength and endurance increases by swim training [33] and inspiratory muscle performance increases by inspiratory muscle training [34], respectively. Recently Cooper et al. [35] concluded that respiratory muscle training can reduce the sensations of breathlessness during exercise in healthy young adults, independently of a reduction in exercise ventilation. From these results, it is likely that trained vocalists seem to be able to reduce respiratory frequency with greater tidal volume to hypoxia and hypercapnia due to not only lower respiratory chemosensitivity, but also being able to reduce the sensation of breathlessness by means of respiratory muscle training. Since it is well known that blood pressure fluctuates by means of changes of intrathoracic and abdominal pressures with respiratory movement, one of the reasons for the difference in the relationship between ventilatory and SBP responses in the vocalist and control groups observed here could be related to slower respiratory frequency and/or greater tidal volume because, in recumbent humans, the rise in abdominal pressure which takes place during natural inspiration causes the collapse of the inferior vena cava and thereby opposes venous return from the legs [36]. However, further investigations are necessary to clarify the complete picture of respiratory and cardiovascular response to hypoxia and hypercapnia in this unique population of trained vocalists.

In conclusion, it is suggested that the magnitude of ventilatory response, but not $\mathrm{HR}$ and $\mathrm{BP}$, to hypoxia and hypercapnia at rest in vocalists is reduced by chronic vocal training including breath control and elongation of phonation for long periods.

We appreciate the cooperation of the subjects in the present study. We also thank Professors S. Kanda and $H$. Nishigaki for assistance throughout the experiments. This study was supported in part by the Grants-in-Aid for Scientific Research from the Japanese Ministry of Education, Culture, Sports, Science and Technology (Grant Nos. 12480009 and 1387007).

\section{REFERENCES}

1. Byrne-Quinn E, Weil JW, Sodal IE, Filley GF, and Grover RF: Ventilatory control in the athletes. J Appl Physiol 30: 91-98, 1971

2. Ohkuwa T, Fujitsuka N, Utsuno T, and Miyamura M: Ventilatory response to hypercapnia in sprint and longdistance swimmers. Eur J Appl Physiol 43: 235-241, 1980

3. Bjurstrom RL and Schoene RB: Control of ventilation in elite synchronized swimmers. J Appl Physiol 63: 1019-1024, 1987

4. Igarashi A: A respiratory adaptation of the Ama. Bull Tokyo Med Dent Univ 16: 327-341, 1969

5. Song SH, Kang DH, Kang BS, and Hong SK: Lung volumes and ventilatory responses to high $\mathrm{CO}_{2}$ and low $\mathrm{O}_{2}$ in the ama. J Appl Physiol 18: 466-470, 1963

6. Florio JT, Morrison JB, and Butt WS: Breathing pattern 
and ventilatory response to carbon dioxide in divers. $J$ Appl Physiol 46: 1076-1080, 1979

7. Grassi B, Ferretti G, Costa M, Ferrigno M, Panzacchi A, Lundgren CEG, Marconi C, and Cerretelli P: Ventilatory responses to hypercapnia and hypoxia in elite breathhold divers. Respir Physiol 97: 323-332, 1994

8. Masuda Y, Yoshida A, Hayashi F, Sasaki K, and Honda Y: The ventilatory responses to hypoxia and hypercapnia in the Ama. Jpn J Physiol 31: 187-197, 1981

9. Masuda Y, Yoshida A, Hayashi F, Sasaki K, and Honda $Y$ : Attenuated ventilatory responses to hypercapnia and hypoxia in assisted breath-hold divers (Funado). Jpn J Physiol 32: 327-336, 1982

10. Miyamura M, Nishimura K, Ishida K, Katayama K, Shimaoka $\mathrm{M}$, and Hiruta S: Is man able to breathe once a minute for an hour. Jpn J Physiol 52: 313-316, 2002

11. Kamon E and Pandolf KB: Maximal aerobic power during laddermill climbing, uphill running, and cycling. J Appl Physiol 32: 467-473, 1972

12. Bender PR, McCullough RE, McCullough RG, Huang SY, Wagner PD, Cymerman A, Hamilton A, and Reeves $\mathrm{JT}$ : Increased exercise $\mathrm{Sa}_{\mathrm{O}_{2}}$ independent of ventilatory acclimatization at $4,300 \mathrm{~m}$. J Appl Physiol 66: 2733-2738, 1989

13. Weil JV, Byrne-Quinn E, Sodal IE, Kline JS, McCullough RE, and Filley GF: Augmentation of chemosensitivity during mild exercise in normal man. J Appl Physiol 33: 813-819, 1972

14. Ohyabu Y, Usami A, Ohyabu I, Ishida Y, Miyagawa C, Arai $T$, and Honda $Y$ : Ventilatory and heart rate chemosensitivity in track-and-field athletes. Eur J Appl Physiol 59: 460-464, 1990

15. Imholz BPM, van Montfrans GA, Settels JJ, van der Hoeven GMA, Karemaker JM and Wieling W: Continuous non-invasive blood pressure monitoring: reliability of Finapres device during the valsalva maneuver. Cardiovasc Res 22: 390-397, 1988

16. Parati G, Gasadei R, Groppelli A, di Rienzo M, and Mancia G: Comparison of finger and intra-arterial blood pressure monitoring at rest and during laboratory testing. Hypertension 13: 647-655, 1989

17. Insalaco G, Romano S, Salvaggio A, Braghiroli A, Lanfranchi P, Patruno V, Donner CF, and Bonsignore G: Cardiovascular and ventilatory response to isocapnic hypoxia at sea level and at 5,050 m. J Appl Physiol 80: 1724-1730, 1996

18. Weil JV, Byrne-Quinn E, Sodal IE, Friesen WO, Underhill B, Filley GF, and Grover RF: Hypoxic ventilatory drive in normal man. J Clin Invest 49: 1061-1072, 1970

19. Hey EN, Lloyd BB, Cunningham DJC, Jukes MGM, and Bolton DPG: Effects of various respiratory stimuli on the depth and frequency of breathing in man. Respir Phys- iol 1: 193-205, 1966

20. Read DJC: A clinical method for assessing the ventilatory response to carbon dioxide. Aust Ann Med 16: 20-32, 1967

21. Keys A, Fidanza F, Karvonen MJ, Kimura N, and Taylor $\mathrm{HL}$ : Indices of relative weight and obesity. J Chron Dis 114: 529-536, 1972

22. Bouhuys A, Proctor DF, and Mead J: Kinetic aspects of singing. J Appl Physiol 21: 483-496, 1966

23. Heller SS, Hicks WR, and Root WS : Lung volumes in singers. J Appl Physiol 15: 40-42, 1960

24. Large J: Observations of the vital capacity of singers. Natl Assoc Teach Sing Bull 28: 34-36, 1971

25. Gould WJ and Okamura $\mathrm{H}$ : Static lung volumes in singers. Am Otol Rhinol Laryngol 82: 89-95, 1973

26. White BD: Singing and science. J Laryngol Otol 96: 141-157, 1982

27. Miyamura M, Yamashita $T$, and Honda Y: Ventilatory response to $\mathrm{CO}_{2}$ rebreathing at rest and during exercise in untrained subjects and athletes. Jpn J Physiol 26: 245-254, 1976

28. Miyamura M and Ishida K: Adaptive changes in hypercapnic ventilatory response during training and detraining. Eur J Appl Physiol 60: 353-359, 1990

29. Blum J, Kanarek D, Gallahan B, Braslow, and Kazemi $\mathrm{H}$ : The effect of training on $\mathrm{CO}_{2}$ ventilatory responsiveness in normal subjects. Am Rev Respir Dis 119 (Suppl): 291.

30. Miles WR: Oxygen consumption during three yogatype breathing patterns. Eur J Appl Physiol 9: 75-82, 1964

31. Stanescu DC, Nemery B, Veriter C, and Marechal C: Pattern of breathing and ventilatory response to $\mathrm{CO}_{2}$ in subjects practicing hatha-yoga. J Appl Physiol 51: 1625-1629, 1981

32. Hanel B and Secher NH: Maximal oxygen uptake and work capacity after inspiratory muscle training: a controlled study. J Sports Sci 9: 43-52, 1991

33. Clanton TL, Dixon GF, Drake J, and Gadek JE: Effects of swim training on lung volumes and inspiratory muscle conditioning. J Appl Physiol 62: 39-46, 1987

34. Inber $O$, Weiner $P$, Azgad $Y$, Rotstein $A$, and Weinstein $Y$ : Specific inspiratory muscle training in well-trained endurance athletes. Med Sci Sports Exerc 32: 12331237, 2000

35. Cooper SJ, Coates JC, Wardrobe-Wong N, and Reed JW: Effects of respiratory muscle training on breathlessness during exercise in healthy young adults. $J$ Physiol (Lond) 520: 57P, 1999

36. Willeput R, Rondeux C, and de Troyer A: Breathing affects venous return from legs in humans. J Appl Physiol 57: 971-976, 1984 